\title{
Parâmetros biofísicos obtidos por sensoriamento remoto em região semiárida do estado do Rio Grande do Norte, Brasil ${ }^{1}$
}

\author{
Joel M. Bezerra ${ }^{2}$, Geber B. de A. Moura ${ }^{3}$, Bernardo B. da Silva ${ }^{4}$, \\ Pabricio M. O. Lopes $^{5}$ \& Ênio F. de F. e Silva ${ }^{6}$

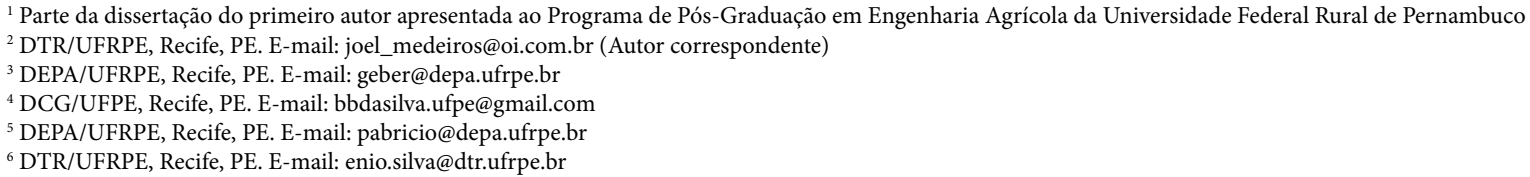

\section{Palavras-chave:}

Landsat

modelagem

mudanças climáticas

uso e ocupação do solo

\begin{abstract}
R E S U M O
Apesar de ser o único bioma brasileiro cujos limites estão restritos ao território nacional, pouca atenção tem sido dada à conservação da diversificada paisagem da Caatinga. Em virtude da carência de dados de campo para monitorar os parâmetros biofísicos da Caatinga em região semiárida do Nordeste brasileiro, este trabalho teve como objetivo avaliar a dinâmica espaço-temporal por meio de técnicas e produtos de Sensoriamento Remoto. A área de estudo compreendeu a Unidade de Conservação do Parque Nacional da Furna Feia e suas adjacências, situada entre os municípios de Mossoró e Baraúna (RN, Brasil). Utilizaram-se seis imagens orbitais do TM LANDSAT 5, órbita 216 e ponto 63, no período de 2007 a 2010. Com auxílio da ferramenta Sistema de Informação Geográfica se implementaram os algoritmos com geração das cartas temáticas expressando a variabilidade dos parâmetros de albedo da superfície, NDVI e temperatura de superfície. Os resultados obtidos não só foram consistentes com dados da literatura para os diferentes usos do solo e variações climáticas. Além de demonstrar o potencial das geotecnologias, a compreensão da dinâmica dos padrões espaciais e temporais dos processos biofísicos de interação solo-planta-atmosfera da Caatinga no Semiárido.
\end{abstract}

Key words:

Landsat

modeling

climate change

land use and occupation

\section{Biophysical parameters from remote sensing in semiarid region of Rio Grande do Norte state, Brazil}

\begin{abstract}
A B S T R A C T
Despite being the single Brazilian biome whose limits are restricted to the national territory, little attention has been given to the conservation of the diverse landscape of 'Caatinga'. Given the scarcity of field data to monitor the biophysical parameters of vegetation of 'Caatinga' in semiarid regions of northeastern Brazil, this study aimed to evaluate the seasonality of spatial dynamics, by means of techniques and products of Remote Sensing. The study area included the conservation unit of the National Park of the Furna Feia and its adjacencies, being situated in the municipalities of Mossoró and Baraúna (RN, Brazil). Six orbital images of TM LANDSAT 5, orbit 216 and paragraph 63 taken during the period 2007 to 2010 were used. With the aid of the tool Geographic Information System algorithms were implemented with the generation of thematic maps expressing the variability of the parameters of surface albedo, Normalized Difference Vegetation Index (NDVI) and surface temperature. The results were consistent with literature data for different soil uses and climatic variations. These results demonstrate the potential of the geotechnologies for understanding the dynamics of the spatial and temporal patterns of biophysical processes of interaction soil-plant-atmosphere of the semi-arid 'Caatinga'.
\end{abstract}

\section{INTRODUÇÃO}

A necessidade de modelagens de parâmetros (hídricos, edáficos e vegetativos) da superfície e da atmosfera, aumenta com as mudanças climáticas e a presença de ação antrópica, voltada ao uso e ocupação do solo.

Nos últimos anos o Sensoriamento Remoto (SR) tem assumido grande importância no monitoramento de diversos fenômenos meteorológicos e ambientais oferecendo suporte nas previsões de tempo e melhor entendimento das mudanças climáticas, além de auxiliar no planejamento agroecológico. Como consequência, tem-se tornado ferramenta poderosa para a obtenção de informações necessárias ao manejo, gerenciamento e gestão de recursos naturais (Bezerra et al., 2011; Gómez et al., 2011; Cunha et al., 2012).

A determinação de parâmetros biofísicos da superfície por técnicas e ferramentas avançadas de sensoriamento remoto com dados mínimos da superfície terrestre, vem sendo aplicada em 
distintos ecossistemas e manejo de grandes áreas destacandose como boa alternativa para obtenção em escala regional, demonstrando resposta espectral de distintos usos sobre áreas de superfície heterogênea (Teixeira et al., 2009; Lopes et al., 2010).

Nas últimas décadas têm sido propostos algoritmos para estimativa de parâmetros biofísicos levando-se em consideração a variabilidade espacial dos componentes espectrais e energéticos à superfície, que ocorrem na interface solo-vegetação-atmosfera. Neste contexto, em estudos mais recentes (Giongo et al., 2010; Lopes et al., 2010; Bezerra et al., 2011; Oliveira et al., 2012) estimaram, de forma simples e eficaz, alguns parâmetros biofísicos da superfície, dentre os quais o albedo da superfície, o Normalized Difference Vegetation Index (NDVI) e a temperatura da superfície utilizando-se a técnica de sensoriamento remoto com imagens TM Landsat 5.

Em sistemas ecológicos o albedo controla as condições microclimáticas das culturas e a absorção de radiação, afetando aspectos físicos e fisiológicos, tais como o balanço de energia, evapotranspiração, fotossíntese e respiração (Wang et al., 2001). Esta afirmativa evidencia que a determinação do albedo é um parâmetro importante no estudo de mudanças climáticas e impactos ambientais (Silva et al., 2005).

O índice de vegetação NDVI, por outro lado, é utilizado para destacar e caracterizar a vegetação que ocorre em uma área; consequentemente, a umidade do solo, servindo para realçar a biomassa vegetal (Bezerra et al., 2011). Este índice pode, também, ser utilizado para auxiliar estudos que tratem de temática da desertificação, além de avaliar a dinâmica espacial de corpos hídricos.

A temperatura da superfície é notadamente influenciada por variações no clima cuja estimativa é de grande interesse em trabalhos práticos, como os estudos de mudanças climáticas e o monitoramento agrometeorológico e ambiental podendo contribuir em programas de irrigação e de gestão dos recursos hídricos, além do monitoramento de mudanças do uso do solo e na vegetação (Weng \& Quattrochi, 2006; Julien \& Sobrino, 2009).

Apesar de ser o único bioma natural brasileiro inteiramente restrito ao território nacional, pouca atenção tem sido dada à conservação da diversificada e marcante paisagem de Caatinga. Outro aspecto relevante é que, o mesmo considerando a contribuição de sua biota, a grande biodiversidade tem sido, ainda assim, subestimada. De acordo com Garda (1996), somente a presença da vegetação de Caatinga adaptada às condições locais, tem impedido a transformação do Nordeste brasileiro num imenso deserto.

Em virtude da importância e da carência de dados de campo para monitorar a dinâmica espaço-temporal da Caatinga em regiões semiáridas do Nordeste brasileiro, pesquisas com sensoriamento remoto permitem compreender o comportamento dos parâmetros biofísicos, face às mudanças climáticas e ações antropogênicas.

Este trabalho propôs avaliar a dinâmica espaço-temporal dos parâmetros biofísicos (albedo da superfície, NDVI e temperatura da superfície), na área de Caatinga do Parque Nacional da Furna Feia e suas adjacências, por meio de técnicas e produtos de sensoriamento remoto.

\section{MATerial e Métodos}

A área de estudo abrange a Unidade de Conservação (UC) do Parque Nacional da Furna Feia (PNFF) e suas adjacências (Figura 1) totalizando 8.494,36 ha situados entre as coordenadas $4^{\circ} 58^{\prime} 33^{\prime \prime}$ e $5^{\circ} 08^{\prime} 57^{\prime \prime}$ de latitude Sul e $37^{\circ} 23^{\prime} 03^{\prime \prime}$ e $37^{\circ} 38^{\prime} 53^{\prime \prime}$ de longitude Oeste, contemplando parte da área dos municípios de Mossoró e Baraúna no Estado do Rio Grande do Norte. O PNFF foi elaborado pela base avançada compartilhada do Centro Nacional de Pesquisa e Conservação de Cavernas (CECAV), vinculada ao Instituto Chico Mendes de Conservação da Biodiversidade (ICMBio), criado oficialmente pelo Decreto de 5 de junho de 2012, publicado no Diário Oficial da União.

No mesmo Decreto também foi definida sua Zona de Amortecimento (ZA), de 25.322 ha (Figura 1), que abrange áreas circunvizinhas de florestas nativas conservadas, além de afloramentos calcários nos quais as atividades humanas praticadas podem colocar em risco a integridade ecológica ou comprometer o alcance continuado dos objetivos do parque, sujeita a regime especial de proteção.

O bioma que caracteriza o PNFF é a Caatinga, sendo uma área bem preservada da vegetação xerófita caducifólia brasileira, com fauna e flora ricas e exuberantes, com fisionomia de caatinga hiperxerófila caducifólia caracterizando, então, um ecossistema com espécies típicas do semiárido nordestino, além de também se encontrar afloramentos calcários conservados. A área de estudo contempla parte da reserva legal da antiga Fazenda Maísa, hoje Projeto de Assentamento Maísa. Este parque é considerado rico patrimônio natural representando a maior UC em Caatinga e a maior entre as de proteção integral do Estado considerando-se apenas os ambientes terrestres (Bento et al., 2011).

Segundo Bento et al. (2011), os levantamentos apresentados, mesmo sendo preliminares, sinalizam uma biodiversidade ímpar: 105 espécies de plantas, distribuídas em 83 gêneros e 42 famílias, sendo 22 espécies endêmicas da Caatinga. Destaca-se que várias espécies constam na lista oficial da flora ameaçada de extinção sendo a formação vegetal predominante do tipo Caatinga arbustivo-arbórea, com alto grau de cobertura do solo.

De acordo com a classificação de Koppen, o clima predominante na região é do tipo BSw'h', caracterizado por ser muito quente e semiárido, com a estação chuvosa no verão que se atrasa para outono. $\mathrm{O}$ índice pluviométrico médio anual é de $677 \mathrm{~mm}^{-1} o^{-1}$ e a temperatura média do ar de $27,4^{\circ} \mathrm{C}$ (Amaro Filho, 1991).

Na Figura 2 se apresentam o balanço hídrico climatológico e o armazenamento de água no solo para a estação de Mossoró, $\mathrm{RN}$ ( $5^{\circ} 33^{\prime} 03^{\prime \prime} \mathrm{S}$ e $37^{\circ} 30^{\prime} 56^{\prime \prime} \mathrm{W}$ ), pertencente ao Instituto Nacional de Meteorologia (INMET). Observa-se, na Figura 2A que em pelo menos nove meses ocorre deficiência hídrica. Nos meses de fevereiro a abril o solo volta a armazenar água 


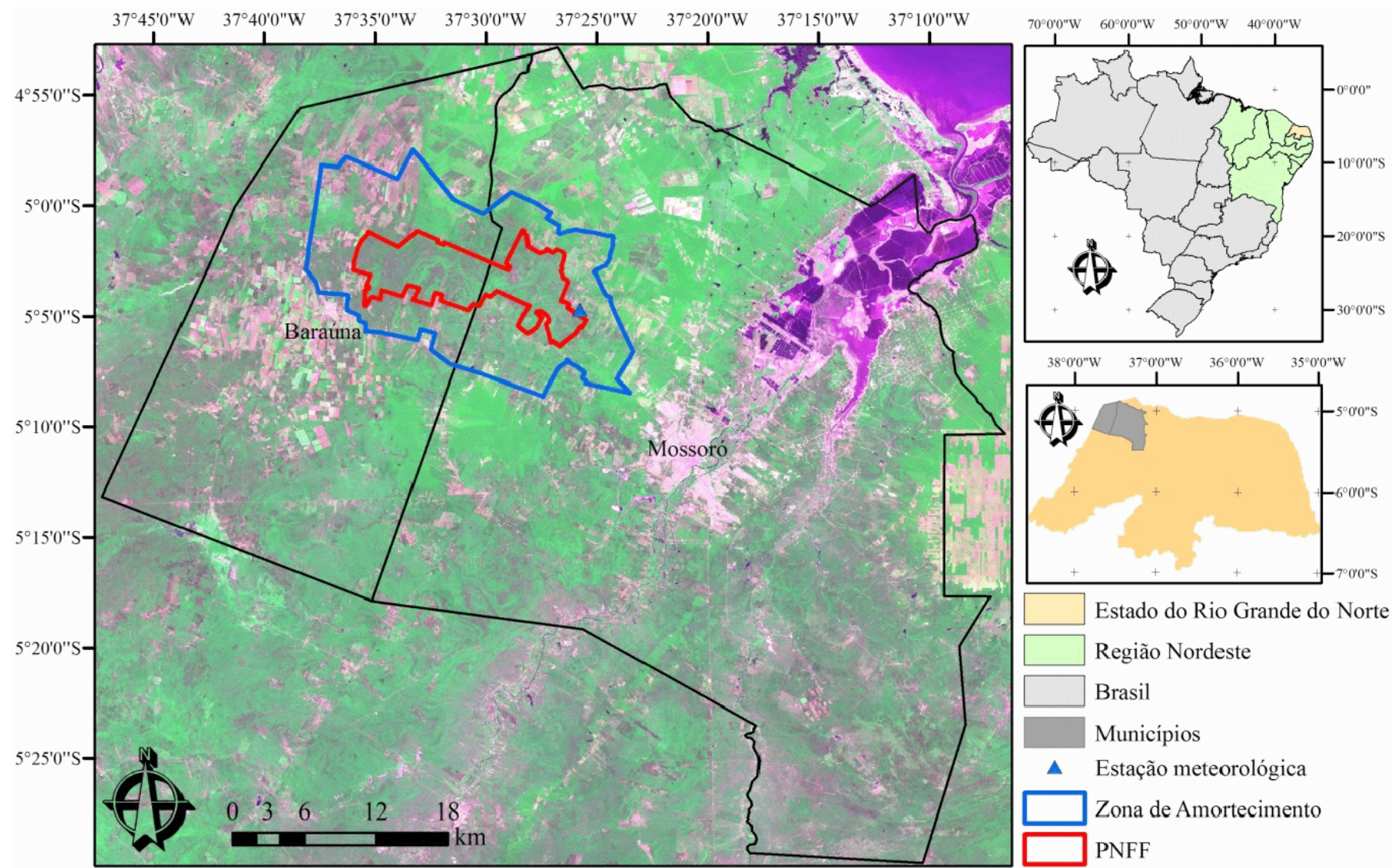

Figura 1. Carta temática da localização do Brasil, região Nordeste, Estado do Rio Grande do Norte, Parque Nacional da Furna Feia (PNFF) e sua respectiva zona de amortecimento, municípios de Mossoró e Baraúna, e estação meteorológica

A.

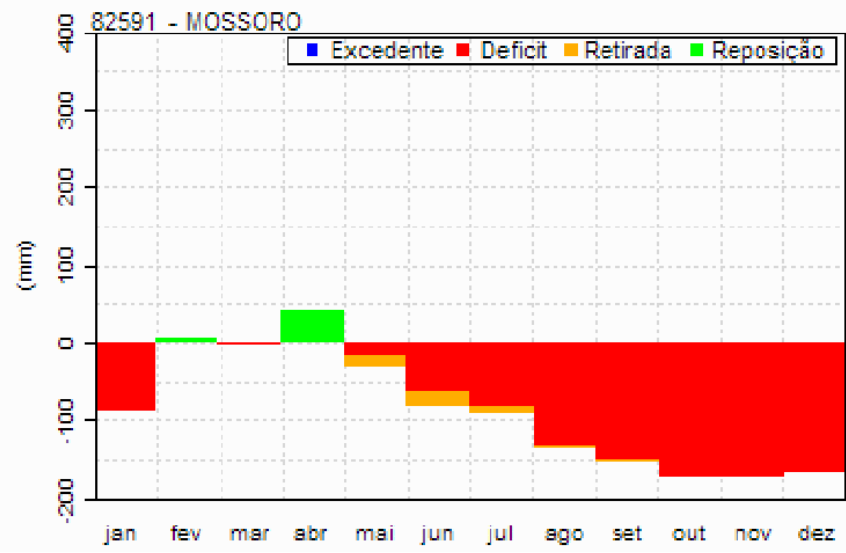

B.

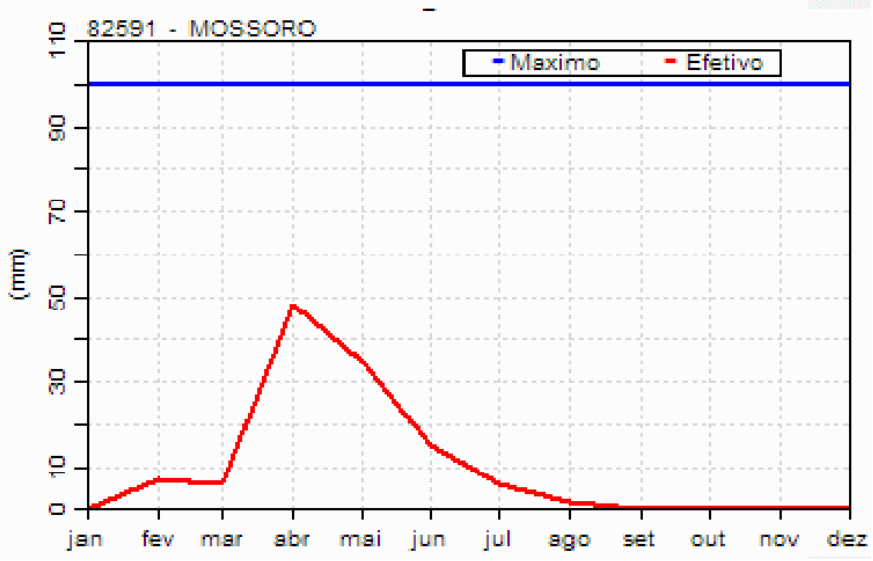

Figura 2. Balanço hídrico climatológico (A) e armazenamento de água no solo (B) do Município de Mossoró, RN. Fonte: INMET

chegando a quase $50 \mathrm{~mm}$ (Figura 2B), com exceção do mês de março quando ocorre um pequeno déficit hídrico.

Os solos do PNFF são classificados como Cambissolo e Neossolo Litólico originados do calcário da formação Jandaíra (Brasil, 1968).

\section{Dados orbitais}

Para estimar os parâmetros biofísicos utilizaram-se imagens do mapeador temático (TM), do satélite Landsat 5 (Tabela 1), adquiridas junto à Divisão de Geração de Imagens do Instituto
Nacional de Pesquisas Espaciais (INPE), U.S. Geological Survey (USGS) e a National Aeronautics and Space Administration (NASA) em que se obtiveram duas imagens por órgão, mediante a disponibilidade de informações.

$\mathrm{Na}$ Tabela 1 tem-se apresentado os coeficientes de calibração e as irradiâncias espectrais $\left(\mathrm{k}_{\lambda_{\mathrm{i}}}\right)$ das bandas reflectivas (bandas $1,2,3,4,5$ e 7 ).

As imagens utilizadas para implementação dos algoritmos correspondem à órbita 216 , ponto 63 , em datas e detalhes especificados na Tabela 2. 
Tabela 1. Coeficientes de calibração mínimos (a), máximos (b) e irradiâncias espectrais no topo da atmosfera $\left(\mathrm{K}_{\lambda_{1}}\right)$ para o TM Landsat 5

\begin{tabular}{|c|c|c|c|}
\hline \multirow[t]{2}{*}{ Banda } & \multicolumn{2}{|c|}{$\begin{array}{c}\text { Coeficientes de } \\
\text { calibração }\left(\mathrm{W} \mathrm{m}^{-2} \mathrm{sr}^{-1} \mu \mathrm{m}^{-1}\right)\end{array}$} & \multirow{2}{*}{$\begin{array}{c}K_{\lambda_{l}} \\
\left(W m^{-2} \mu m^{-1}\right)\end{array}$} \\
\hline & $a$ & b & \\
\hline 1 (azul) & $-1,52$ & 169 & 1.957 \\
\hline 2 (verde) & $-2,84$ & 333 & 1.826 \\
\hline 3 (vermelho) & $-1,17$ & 264 & 1.554 \\
\hline 4 (IV-próximo) & $-1,51$ & 221 & 1.036 \\
\hline 5 (IV-médio) & $-0,37$ & 30,2 & 215 \\
\hline 6 (IV-termal) & 1,2378 & 15,303 & - \\
\hline 7 (IV-médio) & $-0,15$ & 16,5 & 80,67 \\
\hline
\end{tabular}

Fonte: adaptado de Chander et al. (2009), valores de b e Chander \& Markham (2003) para valores de $K_{\lambda_{1}}$

Realizou-se a seleção das imagens considerando-se a cobertura espacial da área de estudo com a mínima cobertura de nuvens para aplicabilidade da técnica de SR, e uma distribuição temporal que permitisse estudar o comportamento de diferentes meses ao longo do período de 2007 e 2010.

O Modelo Digital de Elevação (MDE) da área de estudo foi obtido no site da Embrapa Monitoramento por Satélite (na opção Brasil em Relevo), do produto Shuttle Radar Topography Mission (SRTM). Trata-se de uma imagem matricial (no formato raster), com dados topográficos de altitude, referente aos mosaicos SB-24-X-C e SB-24-X-D.

O processamento das imagens foi executado com a ferramenta Model Maker do software ERDAS Imagine versão 9.1 e, por fim se utilizou, para a produção final das cartas temáticas, o software ArcGis versão 9.3 sendo as imagens orbitais processadas em projeção geográfica, datum WGS 84 .

Para auxiliar as análises das estimativas dos parâmetros biofísicos gerados, com base na imagem de menor incidência de nebulosidade, gerou-se a carta temática de uso e ocupação do solo pelo método da classificação não supervisionada Isoseg, com auxílio do SPRING 5.2 (Dias \& Mattos, 2009). Desta forma foi possível a vetorização das áreas de vegetação nativa tal como áreas de produção agrícola e demais usos predominantes, para apoiar na discussão dos resultados encontrados.

\section{Dados meteorológicos}

As variáveis meteorológicas diárias (precipitação pluviométrica, radiação global e temperatura do ar), que expressam as condições climáticas locais foram obtidas junto ao INMET, referente à Fazenda experimental Rafael Fernandes, localizada no Município de Mossoró, RN, pertencente à Universidade Federal Rural do Semiárido (UFERSA) na localidade denominada comunidade "Alagoinha" (503” 37" S; $37^{\circ} 23^{\prime} 50^{\prime \prime} \mathrm{W} ; 72 \mathrm{~m}$ ) situada a $13 \mathrm{~km}$ da área de estudo (Lucena et al., 2011).

\section{Parâmetros biofísicos}

A modelagem dos parâmetros biofísicos foi baseada na determinação da estimativa dos valores de albedo da superfície $(\alpha)$, NDVI e na temperatura de superfície $\left(\mathrm{T}_{\mathrm{s}}\right)$.

Inicialmente, processou-se a calibração radiométrica realizando-se o processo de conversão do número digital em radiância espectral monocromática $\mathrm{L}_{\lambda_{\mathrm{i}}}$ para as bandas reflectivas do TM Landsat 5 (bandas 1, 2, 3, 4, 5 e 7) sendo utilizada a seguinte expressão (Eq. 1), proposta por Allen et al. (2002), Chander \& Markham (2003) e Silva et al. (2005):

$$
\mathrm{L} \lambda \mathrm{i}=\mathrm{a}_{\mathrm{i}}+\left(\frac{\mathrm{b}_{\mathrm{i}}-\mathrm{a}_{\mathrm{i}}}{255}\right) \mathrm{ND}
$$

em que:

a e b - radiâncias espectrais mínima e máxima, $\mathrm{W} \mathrm{m}^{-2} \mathrm{sr}^{-1}$ $\mu \mathrm{m}^{-1}$, conforme Tabela 1

ND - número digital do pixel (número inteiro de 0 a 255)

i - bandas $(1,2,3 \ldots$ e 7$)$ do TM Landsat 5

A reflectância planetária de cada banda foi obtida por meio da seguinte expressão (Eq. 2), conforme Chander \& Markham (2003) e Silva et al. (2005):

$$
\rho_{\lambda \mathrm{i}}=\frac{\pi \cdot \mathrm{L}_{\lambda \mathrm{i}}}{\mathrm{K}_{\lambda_{\mathrm{i}}} \cdot \cos Z \cdot \mathrm{d}_{\mathrm{r}}}
$$

em que:

$\rho_{\lambda \mathrm{i}} \quad$ - reflectância planetária de cada banda i

$\mathrm{K}_{\lambda \mathrm{i}}$ - irradiância espectral no topo da atmosfera, $\mathrm{W} \mathrm{m}^{-2}$ $\mu \mathrm{m}^{-1}$, conforme Tabela 1

$$
\begin{array}{ll}
\mathrm{Z} & \text { - ângulo zenital solar } \\
\mathrm{d}_{\mathrm{r}} & \text { - distância relativa terra-sol }
\end{array}
$$

O cálculo do albedo planetário $\left(\alpha_{\text {toa }}\right)$, isto é, o albedo não ajustado à transmissividade atmosférica, foi obtido pela combinação linear das reflectâncias monocromáticas conforme Silva et al. (2005) e Giongo et al. (2010), Eq. 3:

$\alpha_{\text {toa }}=0,293 \rho_{1}+0,274 \rho_{2}+0,233 \rho_{3}+0,157 \rho_{4}+0,033 \rho_{5}+0,011 \rho_{7}$

sendo:

$\rho_{1,} \rho_{2,} \rho_{3,} \rho_{4,} \rho_{5}$ e $\rho_{7}$ - reflectâncias planetárias das respectivas bandas

Tabela 2. Datas e características das imagens TM Landsat 5 utilizadas na determinação da calibração radiométrica

\begin{tabular}{lcccccc}
\hline \multicolumn{1}{c}{ DSA } & $\mathbf{2 7 1}$ & $\mathbf{1 9 3}$ & $\mathbf{3 5 3}$ & $\mathbf{2 1 2}$ & $\mathbf{2 7 6}$ & $\mathbf{2 3}$ \\
Data da Imagem & $28 / 09 / 2007$ & $12 / 07 / 2008$ & $19 / 12 / 2008$ & $31 / 07 / 2009$ & $03 / 10 / 2009$ & $23 / 01 / 2010$ \\
$\mathrm{E}\left(^{\circ}\right)$ & 63,4270 & 49,3430 & 55,1930 & 51,6766 & 63,2147 & 55,0857 \\
Cos Z & 0,89437 & 0,75862 & 0,82108 & 0,78452 & 0,89270 & 0,82001 \\
Hora da Passagem & $12: 33: 35$ & $12: 27: 32$ & $12: 24: 58$ & $12: 29: 43$ & $12: 30: 36$ & $12: 31: 27$ \\
dr & 0,99844 & 0,96754 & 1,03230 & 0,97116 & 1,00128 & 1,03045 \\
\hline
\end{tabular}

DSA - Dia sequencial do ano; E - Ângulo de elevação solar; Z - Ângulo zenital solar; Hora de Passagem: (Tempo central GMT); dr.- Distância relativa terra-sol 
O albedo da superfície ou albedo corrigido ( $\alpha$ ) devido aos efeitos atmosféricos, foi obtido pela expressão (Allen et al., 2002), aplicável a dias de céu claro (Eq. 4):

$$
\alpha_{\text {toa }}=\frac{\alpha_{\text {toa }}-\alpha_{\mathrm{p}}}{\tau_{\mathrm{sw}^{2}}}
$$

sendo:

$a_{\mathrm{p}} \quad$ - reflectância da própria atmosfera, considerado nesta pesquisa, o valor de 0,03 (Bastiaanssen, 2000; Silva et al., 2011);

$\tau_{\mathrm{sW}}$ - transmissividade atmosférica para condições de céu claro, que pode ser obtida pela expressão simplificada (Eq. 5) proposta por Allen et al. (2002).

$$
\tau_{\text {sw }}=0,75+2 \times 10^{-5} \mathrm{Z}
$$

em que:

$\mathrm{Z} \quad$ - altitude (m) de cada pixel, extraída do MDE

O índice de vegetação NDVI é a razão entre a diferença das refletividades do Infravermelho-próximo $\left(\rho_{\mathrm{i} v}\right)$ e do vermelho $\left(\rho_{v}\right)$, e sua soma (Eq. 6).

$$
\mathrm{NDVI}=\frac{\rho_{\mathrm{iv}}-\rho_{\mathrm{v}}}{\rho_{\mathrm{iv}}+\rho_{\mathrm{v}}}
$$

correspondem, respectivamente, às bandas 4 e 3 do TM Landsat 5.

A temperatura da superfície ( $T_{s}$ ) foi estimada em função da temperatura de brilho que corresponde à radiância registrada pelo sensor do satélite e calculada pela Eq. de Planck invertida, válida para um corpo negro (Souza \& Silva, 2005; Gomes et al., 2009). Como cada pixel não emite radiação eletromagnética como um corpo negro, é necessário introduzir a emissividade de cada pixel na banda termal $\left(\varepsilon_{\mathrm{NB}}\right)$, do espectro eletromagnético $(10,4-12,5 \mu \mathrm{m})$. Segundo Allen et al. (2007), a $\varepsilon_{\mathrm{NB}}$ pode ser obtida, para NDVI > 0, em função do Índice de Área Foliar (IAF), conforme a Eq. 7 .

$$
\varepsilon_{\mathrm{NB}}=0,97+0,00331 \mathrm{IAF}
$$

com validade para IAF $<3$ e, no caso em que IAF $>3$, considerase $\varepsilon_{\mathrm{NB}}=0,98$ e, para corpos de água (NDVI $\left.<0\right), \varepsilon_{\mathrm{NB}}=0,99$, segundo recomendação de Allen et al. (2002). A temperatura da superfície $\left(\mathrm{T}_{\mathrm{s}}\right)$ em Kelvin $(\mathrm{K})$ é uma função da $\mathrm{L}_{\lambda, 6}$ e da $\varepsilon_{\mathrm{NB}}$, obtida pela Eq. 8:

$$
\mathrm{T}_{\mathrm{s}}=\frac{\mathrm{K}_{2}}{\ln \left(\frac{\varepsilon_{\mathrm{NB}} \mathrm{K}_{1}}{\mathrm{~L}_{\lambda, 6}}+1\right)}
$$

em que, segundo Chander \& Markhan (2003), $\mathrm{K}_{1}=607,76$ $\mathrm{Wm}^{-2} \mathrm{sr}^{-1} \mu \mathrm{m}^{-1}$ e $\mathrm{K}_{2}=1.260,56 \mathrm{~K}$, são constantes de calibração da banda termal do TM Landsat 5 .

\section{Análise estatística}

Todas as estimativas dos parâmetros biofísicos foram avaliadas segundo estatística descritiva dos principais índices estatísticos (média, mediana, máximo, mínimo, moda, desvio padrão e coeficiente de variação).

\section{Resultados e Discussão}

Observa-se, na carta temática do uso e ocupação do solo (Figura 3) que a área estudada constitui uma área bastante heterogênea, formada sobretudo por áreas de vegetação nativa em dois níveis (“densa e rala”, respectivamente as vegetações nativa 1 e nativa 2 ), áreas agrícolas que apresentam agricultura irrigada e solo exposto, além da presença de áreas urbanizadas (comunidades rurais).

Na Figura 4 verifica-se a distribuição espacial do MDE da superfície com a representação da hipsometria da área de

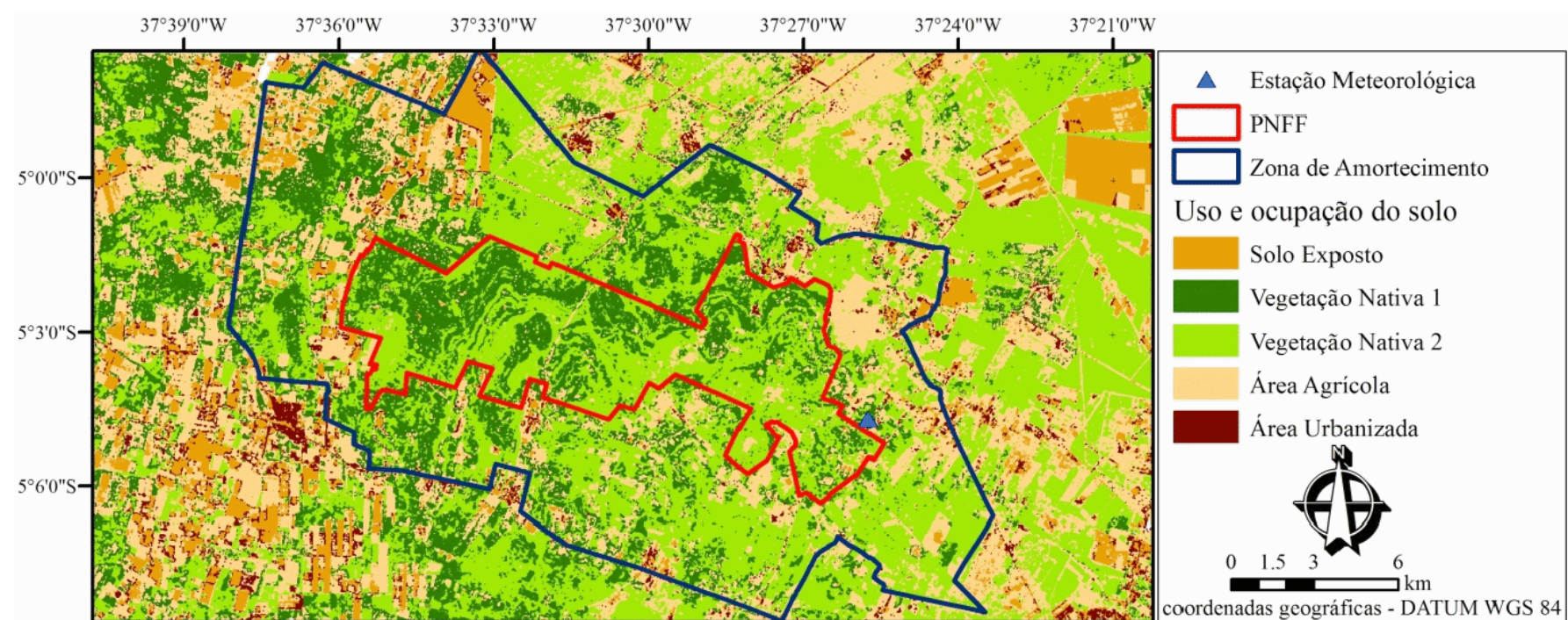

Figura 3. Carta temática de uso e ocupação do solo do Parque Nacional da Furna Feia (PNFF) e sua respectiva zona de amortecimento 


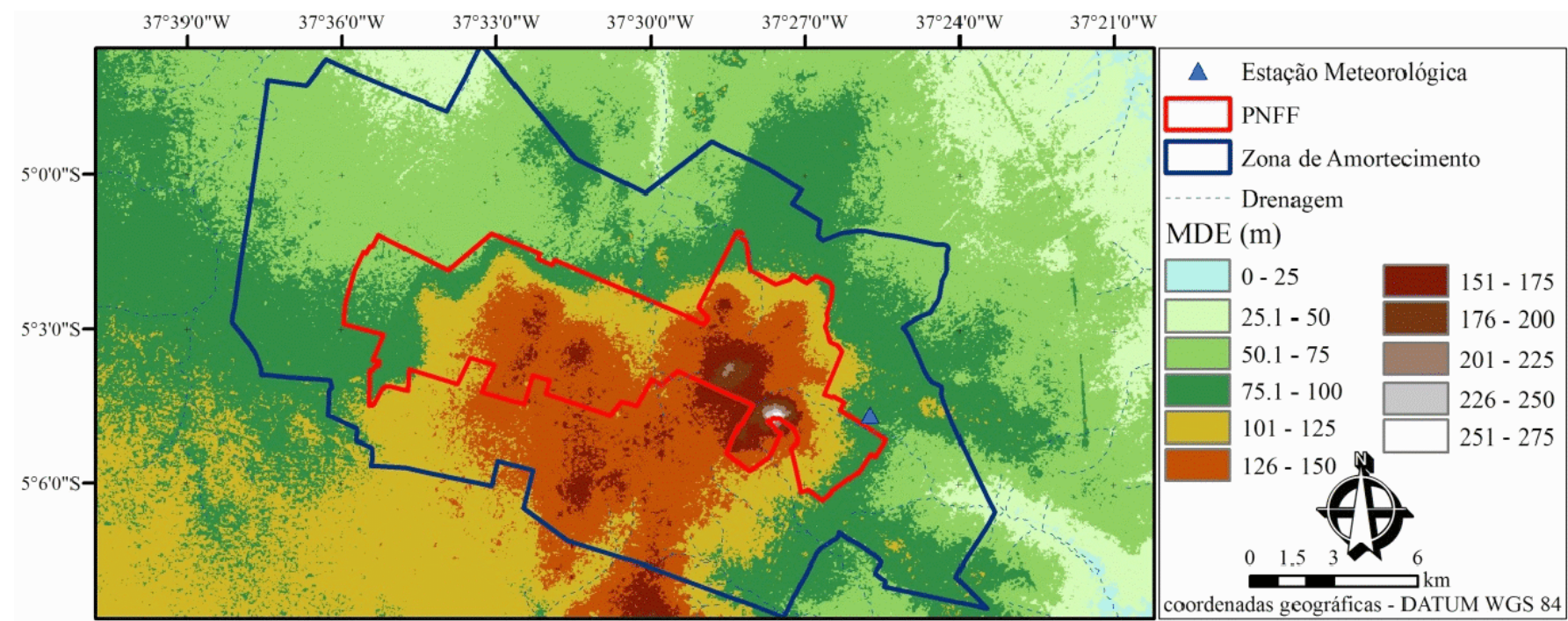

Figura 4. Carta temática de hipsometria do Parque Nacional da Furna Feia (PNFF) e localização da estação meteorológica

estudo, sendo marcada por significativas altitudes na área PNFF, com a presença da serra Mossoró, verificada pela classe de cor branca (251-275).

Relacionando as Figuras 3 e 4 observa-se que as atividades antrópicas predominam a oeste do PNFF apresentando relevo suave ondulado favorecendo o desenvolvimento das atividades de agricultura.

Na configuração gráfica da Figura 5A, B e C verificam-se a indicação das datas imageadas e as variações sazonais diárias da radiação solar global incidente $\left(\mathrm{MJ} \mathrm{m}^{-2}\right)$, temperatura média do $\operatorname{ar}\left({ }^{\circ} \mathrm{C}\right)$ e precipitação $(\mathrm{mm})$. O período estudado foi de 05/06/2007 a 27/06/2010, percebendo-se ausência (falha) de dados no período de 26/04/2009 a 18/05/2009 devido, provavelmente, a um problema no sistema de coleta de dados.

Verificou-se que os maiores valores de radiação solar global incidente foram obtidos durante o período de estiagem em razão da baixa incidência da nebulosidade e reduzida presença de gases de ação atenuante, mas se observa, na temperatura média do ar, um aumento suave no primeiro semestre de 2010 apresentando comportamento semelhante ao da radiação solar global.

Observou-se que as datas imageadas compreendem períodos de estiagens (28/09/2007; 19/12/2008 e 03/10/2009); ou finalizações dos eventos chuvosos (12/07/2008; 31/07/2009 e 23/01/2010).

Da mesma forma que o NDVI, o albedo da superfície quando avaliado de forma sazonal e em longo prazo, pode ser importante indicador de desertificação e de redução de fitomassa da Caatinga. A Figura 6 detalha a variação sazonal da distribuição espacial do albedo da superfície.

Os maiores valores foram detectados no período de estiagem (Figuras 6A, C e E) nas áreas de solo exposto $(0,30$ a 0,35$)$ constatando-se ainda a presença de nuvens (Figuras $8 \mathrm{C}$ e E) marcada pelos valores entre 0,40 e 0,45 e suas respectivas áreas sombreadas com valores próximos a zero $(<0,05)$ subestimando os valores reais da superfície.
Em geral, as áreas com cobertura vegetal de Caatinga apresentaram albedo no intervalo de 0,10 a 0,15 (Figuras 6B, D e $\mathrm{E})$, enquanto nas áreas irrigadas ocorreram valores no intervalo de 0,15 a 0,25 (Figuras $6 \mathrm{~A}, \mathrm{C}, \mathrm{E}$ e F); a cobertura vegetal de Caatinga mais densa no período de estiagem apresentou valores entre 0,15 e 0,20 (Figuras $6 \mathrm{~A} \mathrm{e} \mathrm{C),} \mathrm{devido} \mathrm{à} \mathrm{perda} \mathrm{da} \mathrm{parte} \mathrm{aérea}$ do dossel foliar. A classe de 0,25 a 0,30 representa as áreas de solo exposto (Figuras 6A).

Rodrigues et al. (2009), obtiveram valores oscilando de 0,26 a 0,36 de albedo da superfície em solo exposto. A cobertura vegetal de Caatinga apresentou valores de 0,10 a 0,15 , corroborando com valores similares aos obtidos no presente estudo.

Silva \& Bezerra (2006) observaram, em duas imagens TM Landsat 5 em dezembro de 2000 e outubro de 2001 para uma porção do lago de Sobradinho - Bahia, em algumas áreas irrigadas com fruticultura e vegetação nativa típica do bioma Caatinga, valor médio de albedo da superfície de 0,22. As duas imagens utilizadas apresentaram, ainda, para solos desprovidos de cobertura, albedos da superfície superiores a 0,28 . Os valores detectados no presente estudo variaram de 0,10 a 0,35 (Figuras 6A, C, D e E).

É provável que a diversidade ecológica e a densidade do bioma Caatinga presentes na região de Sobradinho na Bahia sejam distintas da cobertura vegetal de Caatinga presente no Rio Grande do Norte. Desta forma, o PNFF apresenta densidade superior de biomassa, pois a parcela de energia refletida é inferior, função da fração de absorção fotossintética da vegetação presente. Observou-se que o maior valor de albedo da superfície médio encontrado foi de 0,15 em data mensal próxima ao estudo de Silva \& Bezerra (2006).

Os valores de albedo da superfície encontrados para as cenas em estudo apresentam baixa variabilidade espacial estando associados ao uso e ocupação do solo e à cobertura vegetal heterogênea de Caatinga preservada do parque da Furna Feia. Enquanto a variação temporal foi afetada pelas mudanças 
A.
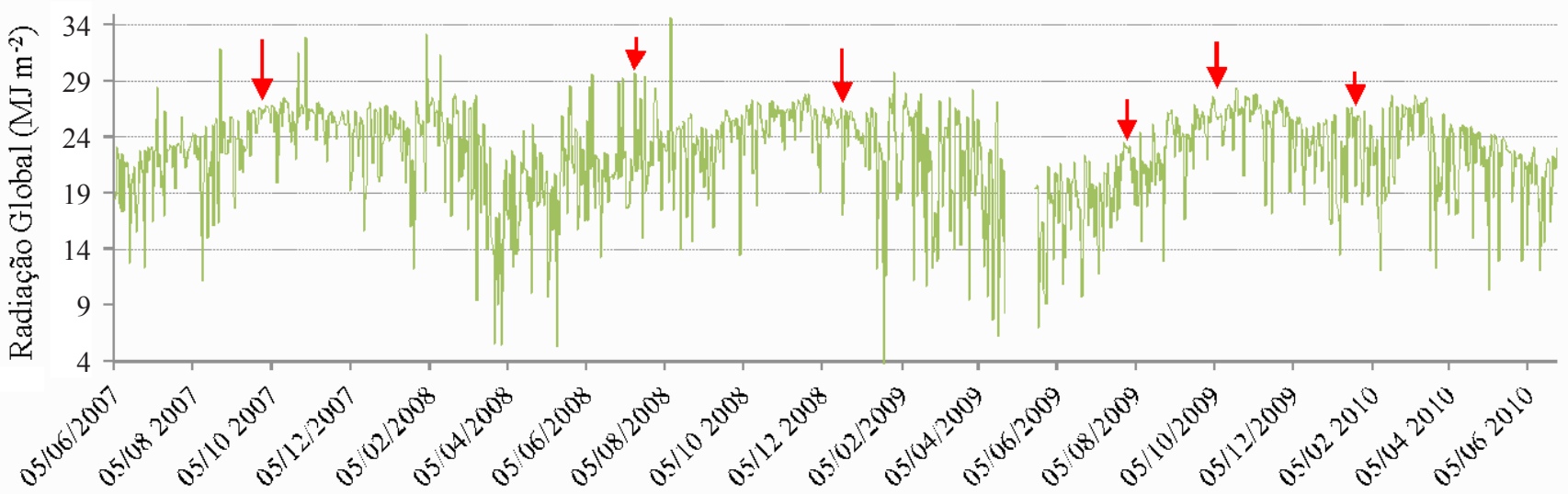

B.
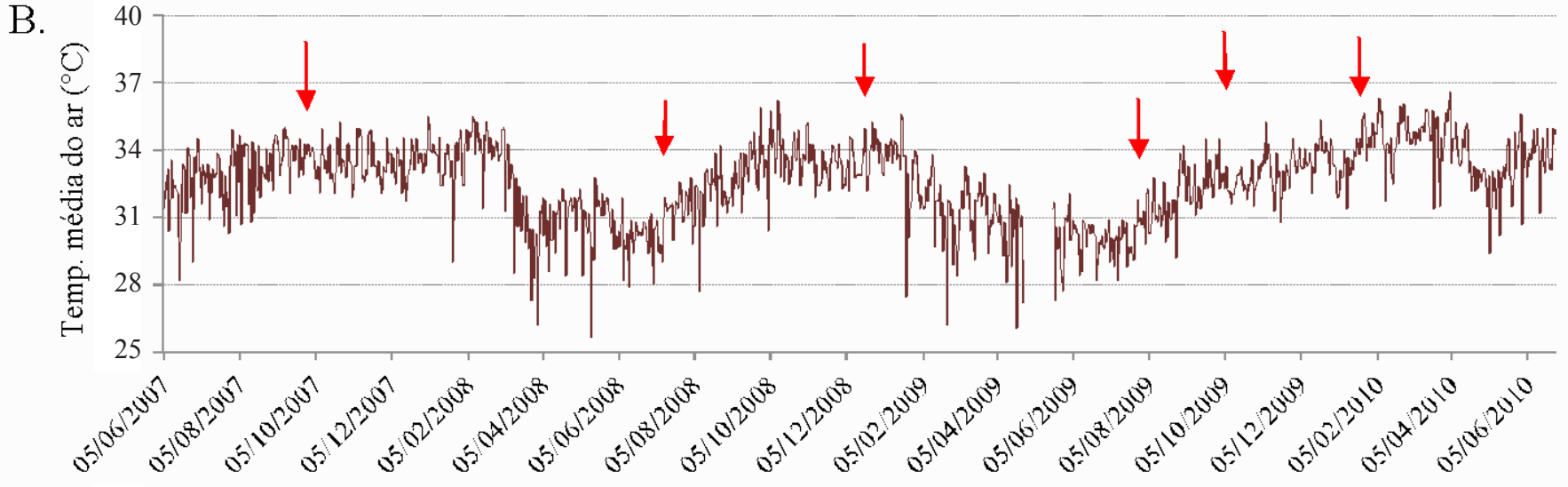

C.

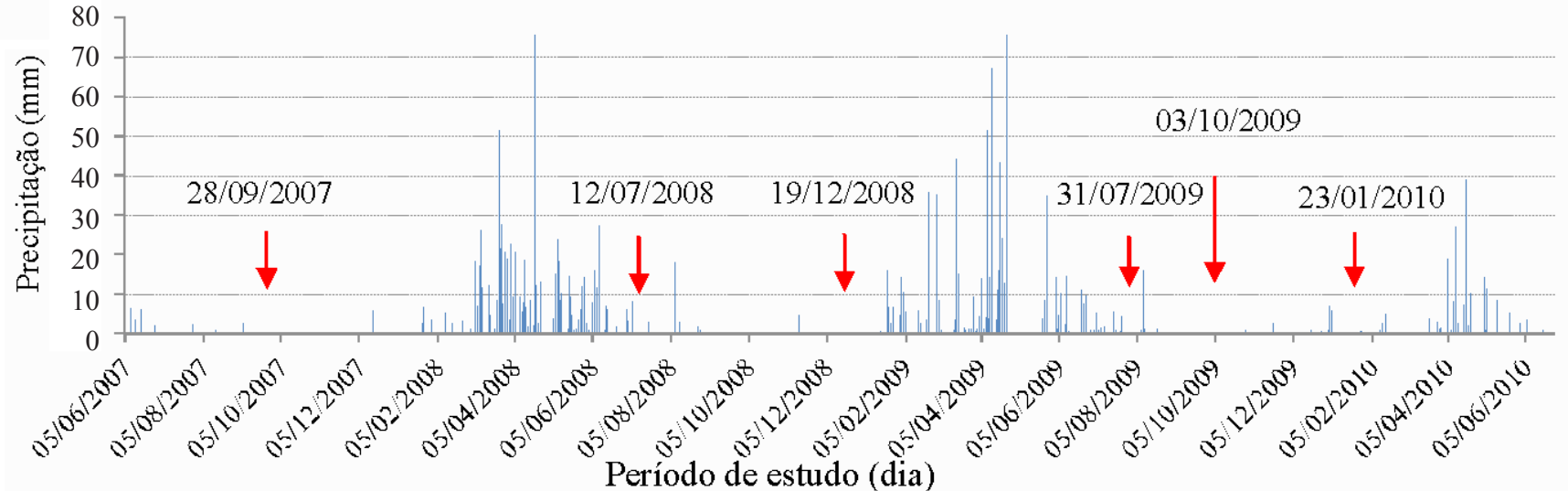

Figura 5. Variação sazonal diária da radiação solar global incidente $\left(\mathrm{MJ} \mathrm{m} \mathrm{m}^{-2}\right)$ - A, temperatura média do ar $\left({ }^{\circ} \mathrm{C}\right)$ - B e precipitação $(\mathrm{mm})$ - C da área de estudo e indicação das datas imageadas

climáticas locais (períodos prolongados de estiagens), além da presença da ação antrópica pelo manejo das áreas agrícolas adjacentes.

O entendimento de diversos processos biofísicos e a distribuição espacial dos fluxos superficiais em um sistema agrícola ou mesmo em um sistema ecológico, como a Caatinga, estão associados à quantidade de biomassa que regula o balanço de radiação no interior do dossel e os processos de troca de energia e de dióxido de carbono $\left(\mathrm{CO}_{2}\right)$ com a atmosfera. A fim de obter a resposta espectral da biomassa da superfície vegetada se utilizam de índices de vegetação.

O NDVI, da mesma forma que o índice de área foliar, determina a percentagem de cobertura do terreno por vegetação sendo reconhecidamente bons estimadores espectrais de algumas características dos dosseis de plantas (Silva, 2009). A Figura 7 apresenta a dinâmica sazonal da variabilidade espacial do índice de vegetação de NDVI.

Os menores valores de NDVI $(0-0,2)$ estão situados nas manchas a leste, oeste e noroeste ao PNFF (Figuras 7A, C, E e F), representadas pela presença de solo exposto, pequenos aglomerados urbanos ou mesmo áreas cobertas por vegetações (vegetação nativa 2) caducifólias ralas que não se mantêm verde na estação seca (Figura 3). Enquanto os maiores valores de NDVI $(0,7-0,8)$ foram detectados nos dias em que ocorreram eventos chuvosos (Figuras 7B, D e F) com magnitudes que possibilitaram condições favoráveis à resiliência e ao desenvolvimento de biomassa da Caatinga (vegetação nativa 1). Diferentemente nas datas em período de estiagem (Figuras 7A, C e E); classe com 

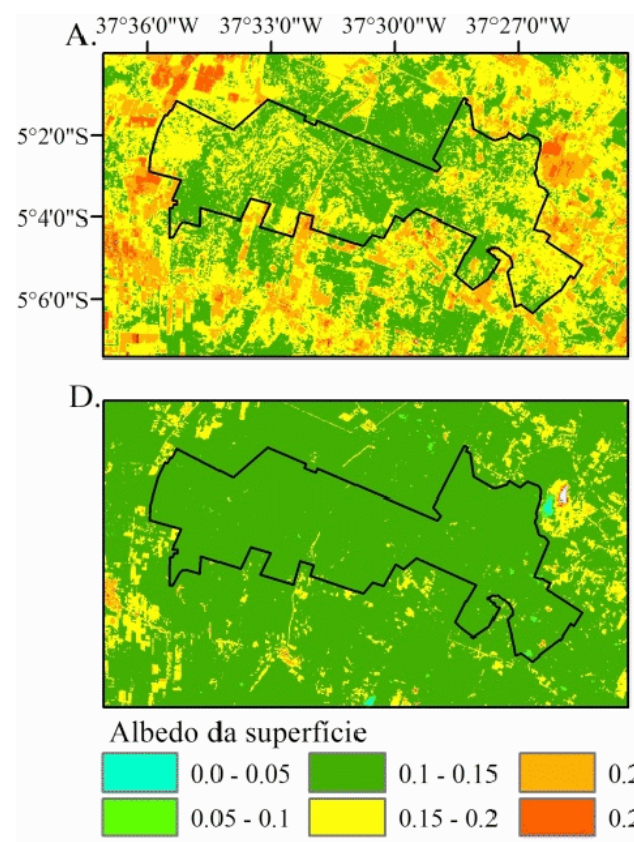

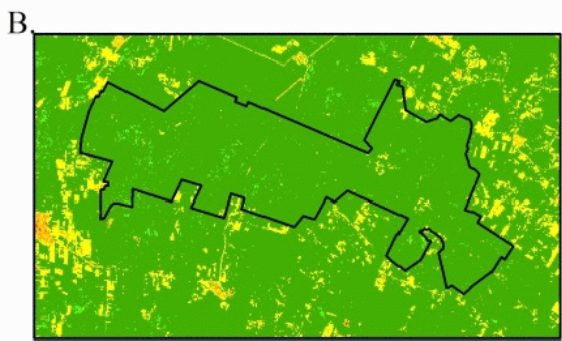

E.

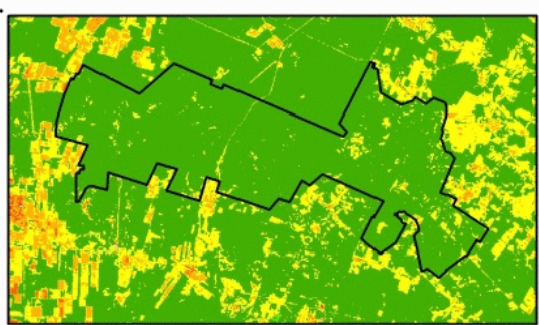

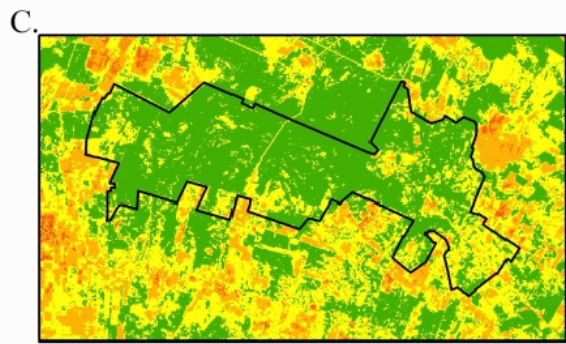

F.
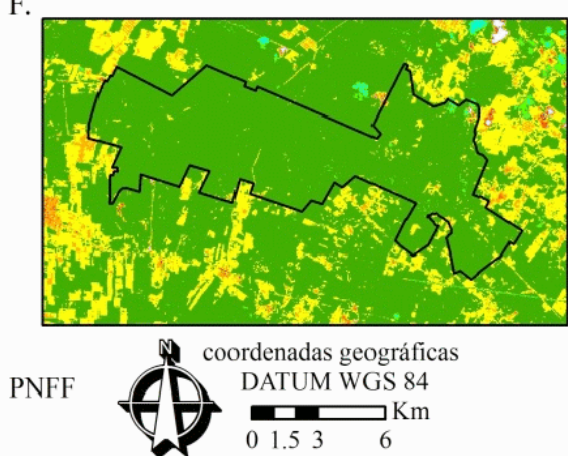

Figura 6. Carta temática sazonal de albedo da superfície de 2007 a 2010 no Parque Nacional da Furna Feia (PNFF): (A). 28/09/2007; (B). 12/07/2008; (C). 19/12/2008; (D). 31/07/2009; (E). 03/10/2009 e (F). 23/01/2010

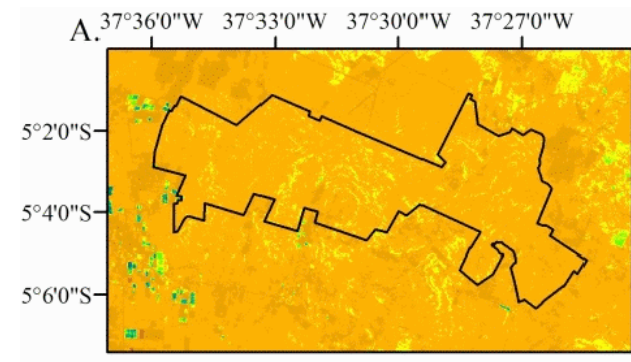

$\mathrm{B}$

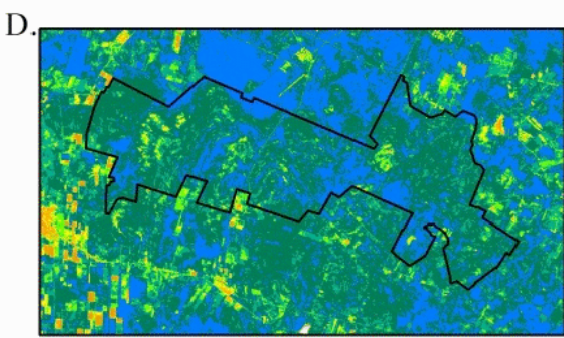

NDVI

E.

$0.0-0.1$

$0.1-0.2$

$0.2-0.3$

$0.3-0.4$
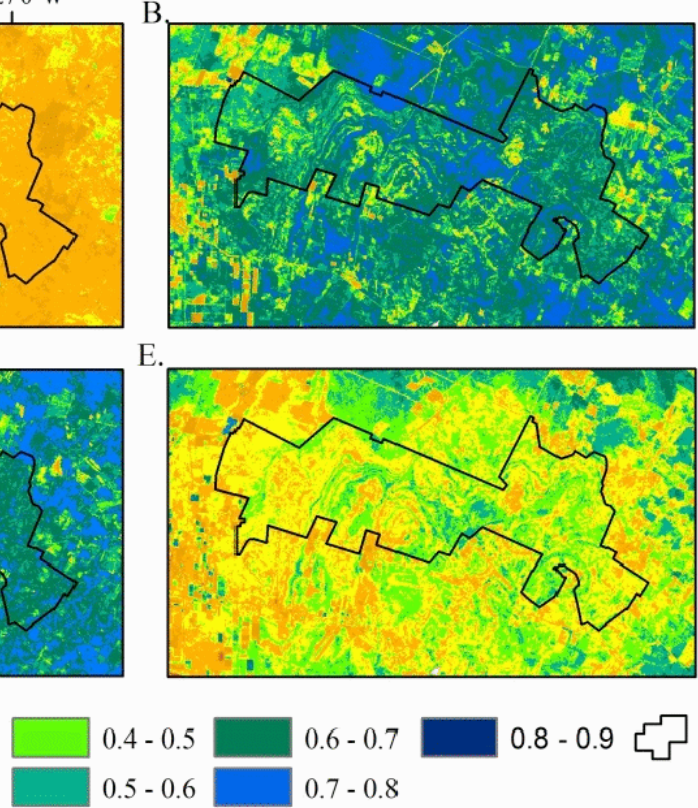

Figura 7. Carta temática da variação sazonal do NDVI de 2007 a 2010 no Parque Nacional da Furna Feia (PNFF):

A. 28/09/2007; B. 12/07/2008; C. 19/12/2008; D. 31/07/2009; E. 03/10/2009 e F. 23/01/2010

a mesma configuração de cor se remete à presença acentuada de áreas agrícolas irrigadas.

Observa-se, na mesma Figura 7, que os maiores valores foram detectados nas datas 12/07/2008 e 31/07/2009 fato este justificado supondo-se ser a precipitação a principal causa dessas modificações em razão da umidade presente no solo em função do declínio do regime de precipitação, além da ocorrência de eventos recentes de chuva próximo ao período de obtenção das duas cenas. Tais averiguações são compatíveis com as realizadas por Silva \& Bezerra (2006) estudando regiões de climas semiáridos.

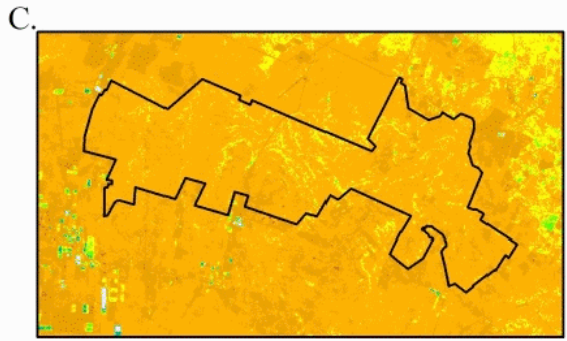

F.
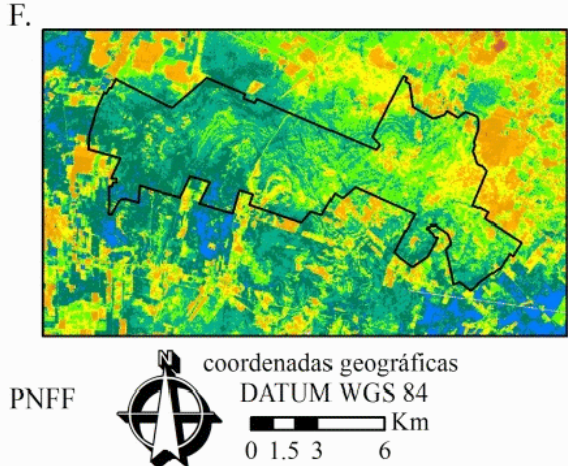

Observando os comportamentos das Figuras 5 e 7, verificase que os valores mais elevados de NDVI, especificamente no período de inverno, estão situados no interior do PNFF, que corresponde à presença de vegetação nativa densa em virtude da elevada produção de biomassa, conforme Barbosa et al. (2006). Opostamente se constata, no período de estiagem, a presença de valores elevados de NDVI fora da área do PNFF, os quais se referem aos talhões do polo agrícola de Baraúna marcados pela fruticultura irrigada.

Tal inversão espacial ocorre pelo mecanismo de defesa fisiológico da vegetação do bioma Caatinga, que se caracteriza 
pela queda das folhas no período de estiagem (Figuras 7A e C), em função do déficit hídrico acentuado nas regiões semiáridas.

Observa-se, na Figura 6 (A e C) e na Figura 7 (A e C), respectivamente, que nos dias 28/09/2007 e 19/12/2008, grande semelhança de comportamento entre os valores e padrões de variabilidade espacial, apresentados para os parâmetros biofísicos NDVI e albedo, fato decorrente de ambas as imagens, apresentarem configuração espectral da superfície referente ao período de estiagem. Enquanto a Figura 6 (B e D) e a Figura 7 (B e D), apresentam, respectivamente nos dias 12/07/2008 e 31/07/2009, padrão espacial similar, em virtude da presença de umidade no solo, tal como a preservação da massa foliar da vegetação.

Rodrigues et al. (2009) encontraram, em estudo realizado na região semiárida do Ceará, na bacia hidrográfica do rio Trussu, nos anos de 2000 e 2001, valores de NDVI na ordem de 0,003 a 0,20 em período de estiagem; já no período de ocorrência de precipitações variou de 0,003 a 0,76 , com predominância de valores na classe de 0,20 a 0,39 . Sendo que os resultados obtidos em ambos os períodos estão inferiores aos detectados neste trabalho, em que se obtiveram valores da ordem de 0,10 a 0,26 no período seco (28/09/2007), enquanto no período chuvoso (31/07/2009) se registraram de 0,66 a 0,79 .

A temperatura de superfície $\left(\mathrm{T}_{\mathrm{s}}\right)$ atua como indicador de áreas propícias à ocorrência de incêndios, cujas condições de estresse hídrico (baixa umidade e elevada insolação), favorecem o agravamento do processo de desertificação, além de dispor de informações ao manejo adequado do solo e planta.

Pelo comportamento da Figura 8 observa-se a espacialização da temperatura da superfície que, de modo geral, ocorre similar à distribuição da cobertura vegetal; contudo estando ainda relacionada à sazonalidade dos parâmetros meteorológicos de radiação solar global incidente, a temperatura do ar e ao regime de precipitação (Figura 5).

Especialmente na Figura 8C (19/12/2008), constatou-se a possível presença de efeitos provenientes da nebulosidade na área de estudo ou, ainda, um erro proveniente do processamento do sensor da banda termal do satélite atenuando a propagação da parcela de energia incidente sobre a superfície do solo, afetando a temperatura da superfície em virtude da transmissividade da camada atmosférica. As demais cartas temáticas de $\mathrm{T}_{\mathrm{s}}$ apresentaram menores temperaturas correspondentes ao período de ocorrência de eventos chuvosos corroborando com o comportamento espectral obtido por Cunha et al. (2012).

As menores $\mathrm{T}_{\mathrm{s}}$ foram registradas em relevo de maiores altitudes sendo representadas pela cobertura vegetal mais densa (Figuras 8B, D e F). Já os maiores valores de $\mathrm{T}_{\mathrm{s}}$ foram obtidos na Figura 8 A (28/09/2007), em que foi marcada por um período de estiagem e superfícies de solo exposto e sobre influência antrópica, além de baixos valores de NDVI (Figura $7 \mathrm{~A}$ ) e elevados valores de albedo (Figura 6A), corroborando com estudos realizados por Lopes et al. (2010), na bacia do rio Brígida - PE, e Cunha et al. (2012), na bacia de São João do Rio do Peixe, PB.

Ainda, relacionando-se as Figuras 6A, 7A e 8A, observa-se que a cobertura vegetal com estresse hídrico tende a absorver menos radiação solar, o que aumenta sua reflectância na faixa espectral do visível (albedo elevado) e a absorver mais na faixa espectral do infravermelho ocasionando menores valores de NDVI e maiores valores de temperatura de superfície. Ao passo que a vegetação verde tem, naturalmente, maior valor de NDVI em função da alta absorção fotossintética da radiação eletromagnética no intervalo de comprimento de onda do vermelho, pela clorofila da biomassa presente (Silva, 2009).
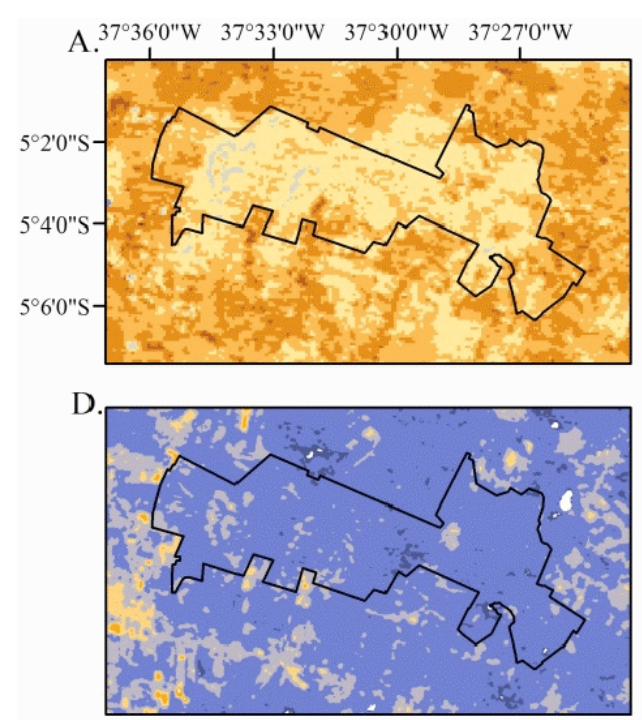

Temperatura de superfície $\left({ }^{\circ} \mathrm{C}\right)$

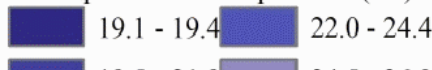

$19.5-21.9$

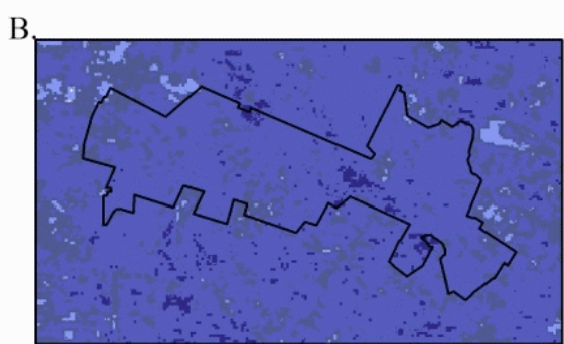

E.

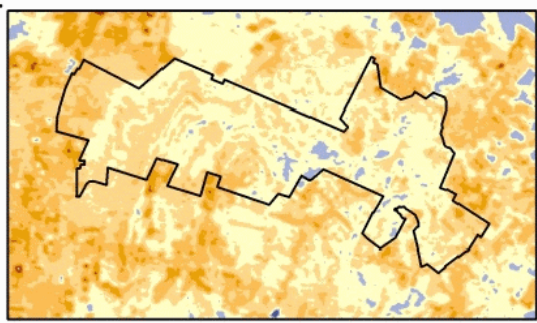

$27.0-29.4$ $29.5-31.9$

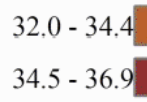

37.0 $39.5-41.9$

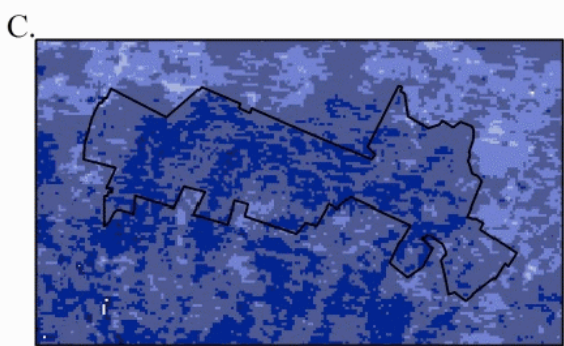

F.

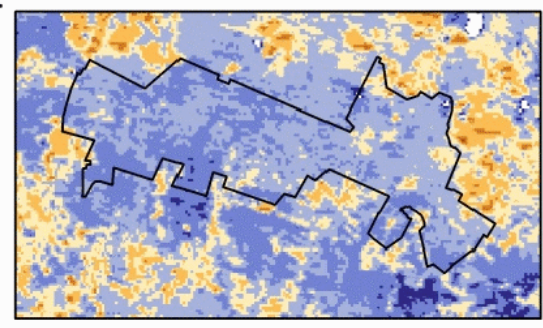

PNFF

Figura 8. Carta temática sazonal de temperatura de superfície $\left({ }^{\circ} \mathrm{C}\right)$ no período de 2007 a 2010 no Parque Nacional da Furna Feia (PNFF): A. 28/09/2007; B. 12/07/2008; C. 19/12/2008; D. 31/07/2009; E. 03/10/2009 e F. 23/01/2010 
Tabela 3. Estatística descritiva dos parâmetros biofísicos estimados para a área do Parque Nacional da Furna Feia (PNFF)

\begin{tabular}{|c|c|c|c|c|c|c|c|c|}
\hline Data da imagem & PB & Média & Mediana & Mín. & Máx. & Moda & DP & CV \\
\hline \multirow{2}{*}{ 28/09/2007 } & Albedo & 0,15 & 0,15 & 0,12 & 0,32 & 0,14 & 0,02 & 0,11 \\
\hline & Ts & 31,72 & 31,48 & 25,01 & 37,66 & 30,65 & 1,53 & 0,01 \\
\hline \multirow[t]{2}{*}{$12 / 07 / 2008$} & NDVI & 0,61 & 0,63 & 0,05 & 0,80 & 0,69 & 0,09 & 0,16 \\
\hline & Ts & 18,34 & 18,14 & 15,82 & 24,18 & 17,98 & 1,00 & 0,00 \\
\hline $19 / 12 / 2008$ & Albedo & 0,15 & 0,14 & 0,11 & 0,32 & 0,13 & 0,02 & 0,12 \\
\hline \multirow{3}{*}{$31 / 07 / 2009$} & Albedo & 0,12 & 0,12 & 0,04 & 0,34 & 0,13 & 0,01 & 0,08 \\
\hline & NDVI & 0,66 & 0,67 & 0,06 & 0,79 & 0,69 & 0,06 & 0,10 \\
\hline & Ts & 25,59 & 25,49 & 23,35 & 30,84 & 25,11 & 0,87 & 0,00 \\
\hline \multirow{3}{*}{ 03/10/2009 } & Albedo & 0,13 & 0,12 & 0,09 & 0,30 & 0,13 & 0,01 & 0,10 \\
\hline & NDVI & 0,38 & 0,38 & 0,12 & 0,65 & 0,38 & 0,07 & 0,19 \\
\hline & Ts & 31,88 & 31,83 & 27,86 & 39,60 & 31,43 & 1,55 & 0,01 \\
\hline
\end{tabular}

Número de observações 95338 pixels; PB - Parâmetro Biofísico; Min - Mínimo; Máx - Máximo; DP - Desvio Padrão; CV - Coeficiente de Variação; NDVI - Normalized DifferenceVegetation Index; $\mathrm{T}_{\mathrm{S}}$ - Temperatura de Superfície $\left({ }^{\circ} \mathrm{C}\right)$

Na Tabela 3 verificam-se os valores dos principais índices estatísticos utilizados para avaliar os parâmetros biofísicos (albedo da superfície, NDVI e temperatura de superfície) estimados na área de estudo do PNFF.

Pode-se observar, na Tabela 3, que os menores valores de coeficiente de variação foram atribuídos à temperatura de superfície com valores inferiores a 0,01 enquanto os maiores valores foram obtidos para o NDVI $(0,21)$. De acordo com o Zwart et al. (2006), valores de CV abaixo de 0,09 indicam extrema homogeneidade no padrão de distribuição espacial.

Entre os parâmetros biofísicos avaliados foram detectados coeficientes de variação da ordem 0,08 a 0,13 para albedo da superfície; 0,10 a 0,21 para o NDVI e 0,0 a 0,01 para a temperatura de superfície. Analisando, de forma isolada, os parâmetros, observa-se que a data 23/01/2010 remete aos maiores valores de CV para o albedo da superfície e NDVI, configurado pelo período de transição da estação chuvosa para seca. Enquanto a Ts, apresentou maior CV para as datas 28/09/2007 e 03/10/2009, marcado pelo período de estiagens.

Desta forma, o NDVI pode ser utilizado como parâmetro indicador da dinâmina espaço-temporal de superfícies heterogêneas, ou seja, distintos usos e ocupações do solo, em virtude da sua elevada sensibilidade de detecção envolver radiação visivel e infra-vermelho em superfície (Silva, 2009; Bezerra et al., 2011).

Observa-se ainda, na Tabela 3, uma grande amplitude nos dados do dia 12/07/2008, fato este promovido pela presença de diversidade da superfície da área (solo exposto, área irrigada, vegetação de Caatinga), além da rápida resposta da cobertura vegetal de Caatinga aos primeiros eventos de precipitação marcando o processo de resiliência natural pelos mecanismos fisiológicos e morfológicos da vegetação de Caatinga.

\section{Conclusões}

1. A variação obtida de albedo da superfície, NDVI e temperatura da superfície quanto aos diferentes usos e ocupação do solo, seguem o padrão esperado e corrobora com a eficiência da capacidade analítica e sinóptica das variáveis geradas pela metodologia utilizada.

2. O uso da ferramenta de SIG e o sensoriamento remoto permitiram identificar diferenças nos padrões espaciais e temporais dos parâmetros biofísicos em resposta ao uso e à ocupação do solo, além das variações climáticas.

3. O algoritmo estimou satisfatoriamente os valores dos parâmetros biofísicos para o bioma Caatinga em semiárido, estando consistentes com observações da literatura.

4. Mediante os primeiros eventos de chuva, a vegetação de Caatinga promoveu elevada produção de biomassa invertendo a dinâmica espacial, ficando constatado o alto poder de resiliência no período de inverno, além da efetiva conservação da vegetação nativa.

\section{Agradecimentos}

Os autores agradecem à Coordenação de Aperfeiçoamento de Pessoal de Nível Superior (CAPES), pela concessão da bolsa de pós-graduação ao primeiro autor; à Universidade Federal Rural do Semiárido (UFERSA), por dispor dos dados meteorológicos e ao Instituto Chico Mendes de Conservação da Biodiversidade (ICMBio), pelo fornecimento de informações técnicas sobre a UC do Parque Nacional da Furna Feia (PNFF).

\section{Literatura Citada}

Allen, R. G.; Tasumi, M.; Trezza, R. Surface energy balance algorithm for land (SEBAL) - Advanced training and users Manual. Version 1.0. Idaho, 2002. 97p. 
Allen, R. G.; Tasumi, M.; Trezza, R. Satellite-based energy balance for mapping evapotranspirationwith internalized calibration (METRIC) - Model. Journal of Irrigation and Drainage Engineering, v.133, p.380-394, 2007.

Amaro Filho, J. Contribución al estudio del clima del Rio Grande do Norte. Madrid: Escuela Técnica Superior de Ingenieros Agrónomos, Universidade Politécnica de Madrid, 1991. 311 . Tese Doutorado

Barbosa, H. A.; Hueti, A. R.; Baethgen, W. E. A 20 - year study of NDVI variability over the Northeast Region of Brazil. Journal of Arid Environments, v.67, p.288-307, 2006.

Bastiaanssen, W. G. M. SEBAL-based sensible and latent heat fluxes in the irrigated Gediz Basin, Turkey. Journal of Hydrology, v.229, p.87-100, 2000.

Bento, D. M.; Cruz, J. B.; Ferreira, R. L.; Veríssimo, C. U.; Xavier Neto, P. Complexo espeleológico da Furna Feia e áreas cársticas adjacentes: a maior concentração de cavernas do Rio Grande do Norte. In: Congresso Brasileiro de Espeleologia, 31, 2011. Ponta Grossa. Anais... Ponta Grossa: SBE, 2011. p.63-72.

Bezerra, M. V. C.; Silva, B. B. da; Bezerra, B. B. Avaliação dos efeitos atmosféricos no albedo e NDVI obtidos com imagens de satélite. Revista Brasileira de Engenharia Agrícola e Ambiental, v.15, p.709-717, 2011.

Brasil. Ministério da Agricultura. Mapa exploratório reconhecimento de solos do estado do Rio Grande do Norte. Rio de Janeiro, 1968. http://eusoils.jrc.ec.europa.eu/ esdb_archive/eudasm/latinamerica/maps/br13011_so.htm. 8 Set. 2013.

Chander, G.; Markham, B. Revised Landsat 5 - TM radiometric calibration procedures and postcalibration dynamic ranges. IEEE Transactions on Geosciences and Remote Sensing, v.41, p.2674-2677, 2003.

Chander, G.; Markham, B. L.; Helder, D. L. Summary of current radiometric calibration coefficients for Landsat MSS, TM, ETM+, and EO-1 ALI sensors. Remote Sensing of Environment, v.113, p.893-903, 2009.

Cunha, J. E. de B. L.; Rufino, I. A. A.; Silva, B. B. da; Chaves, I. de B. Dinâmica da cobertura vegetal para a Bacia de São João do Rio do Peixe, PB, utilizando-se sensoriamento remoto. Revista Brasileira de Engenharia Agrícola e Ambiental, v.16, p.539-548, 2012.

Dias, R. R.; Mattos, J. T. Zoneamento ecológico-econômico no Tocantins: comparação de resultados usando um mesmo método em diferentes datas. Revista Brasileira de Cartografia, v.4, p.351-365, 2009.

Garda, E. C. Atlas do meio ambiente do Brasil. 2.ed. Brasília: Terra Viva/EMBRAPA, 1996. 138p.

Giongo, P. R.; Moura, G. B. de A.; Silva, B. B. da; Rocha, H. R. da; Medeiros, S. R. R. de; Nazareno, A. C. Albedo à superfície a partir de imagens Landsat 5 em áreas de cana-de-açúcar e cerrado. Revista Brasileira de Engenharia Agrícola e Ambiental, v.14, p.279-287, 2010.
Gomes, H. B.; Silva, B. B. da; Cavalcanti, E. P.; Rocha, H. R. da. Balanço de radiação em diferentes biomas de São Paulo mediante imagens Landsat 5. Geociências, v.28, p.153-164, 2009.

Gómez, C.; White, J. C.; Wulder, M. A. Characterizing the state and processes of change in a dynamic forest environment using hierarchical spatio-temporal segmentation. Remote Sensing of Environment, v.115, p.1665-1679, 2011.

Julien, Y.; Sobrino, J. A. The yearly land cover dynamics (YLCD) method: An analysis of global vegetation from NDVI and LST parameters. Remote Sensing of Environment, v.113, p.329-334, 2009.

Lopes, H. L.; Candeias, A. L. B.; Accioly, L. J. O.; Sobral, M. do C. M.; Pacheco, A. P. Parâmetros biofísicos na detecção de mudanças na cobertura e uso do solo em bacias hidrográficas. Revista Brasileira de Engenharia Agrícola e Ambiental, v.14, p.1210-1219, 2010.

Lucena, R. R. M. de; Negreiros, M. Z. de; Medeiros, J. F. de; Grangeiro, L. C.; Marrocos, S. T. P. Crescimento e acúmulo de macronutrientes em melancia 'quetzale' cultivada sob diferentes níveis de salinidade da água de irrigação. Revista Caatinga, v.24, p.34-42, 2011.

Oliveira, L. M. M. de; Montenegro, S. M. G. L.; Antonino, A. C. D.; Silva, B. B. da; Machado, C. C. C.; Galvíncio, J. D. Análise quantitativa de parâmetros biofísicos de bacia hidrográfica obtidos por sensoriamento remoto. Revista Pesquisa Agropecuária Brasileira, v.47, p.12091217, 2012.

Rodrigues, J. O.; Andrade, E.; Teixeira, A. S.; Silva, B. B. da. Sazonalidade de variáveis biofísicas em regiões semiáridas pelo emprego do sensoriamento remoto. Revista Brasileira de Engenharia Agrícola e Ambiental, v.29, p.452-465, 2009.

Silva, B. B. da; Bezerra, M. V. C. Determinação dos fluxos de calor sensível e latente na superfície utilizando imagens TM Landsat 5. Revista Brasileira de Agrometeorologia, v.14, p.174-186, 2006.

Silva, B. B. da; Braga, A. C.; Braga, C. C. Balanço de radiação no perímetro irrigado São Gonçalo, $\mathrm{PB}$ mediante imagens orbitais. Revista Caatinga, v.24, p.145-152, 2011.

Silva, B. B. da; Lopes, G. M.; Azevedo, P. V. de. Determinação do albedo de áreas irrigadas com base em imagens Landsat 5 TM. Revista Brasileira de Agrometeorologia, v.13, p.201211, 2005.

Silva, S. T. A. Mapeamento da evapotranspiração na Bacia Hidrográfica do Baixo Jaguaribe usando técnicas de sensoriamento remoto. Campina Grande: UFCG, 2009. 119p. Tese Doutorado

Souza, J. D.; Silva, B. B. da. Correção atmosférica para temperatura da superfície obtida com imagem TM - Landsat 5. Revista Brasileira de Geofísica, v.23, p.349-358, 2005.

Teixeira, A. H. de C.; Bastiaanssen, W. G. M. Ahmad, M. D.; Bos, M. G. Reviewing SEBAL input parameters for assessing evapotranspiration and water productivity for the LowMiddle São Francisco River basin, Brazil Part B: Application to the large scale. Agricultual and Forest Meteorology, v.149, p.477-490, 2009. 
Wang, S.; Grant, R. F.; Verseghy, D. L.; Black, T. A. Modelling plant carbon and nitrogen dynamics of a boreal aspen forest in CLASS - the Canadian Land Surface Scheme. Ecology Modelling, v.142, p.135-154, 2001.

Weng, Q.; Quattrochi, D. A. Thermal remote sensing of urban areas: An introduction to the special issue. Remote Sensing of Environment, v.104, p.119-122, 2006.
Zwart, S. J.; Bastiaanssen, W. G. M.; Garatuza-Payan, J.; Watts, C. J. SEBAL for detecting spatial variation of water productivity for wheat in the Yaqui Valley, Mexico. In: (ed.) D’Urso, G.; Jochum, M. A. O.; Moreno, J. Earth observation for vegetation monitoring and water management. Maryland: American Institute of Physics, 2006. p.154-161. 